Article

\title{
Pleurotus highking Mushroom Induces Apoptosis by Altering the Balance of Proapoptotic and Antiapoptotic Genes in Breast Cancer Cells and Inhibits Tumor Sphere Formation
}

\author{
Md. Anwarul Haque 1,2,3 and Md. Anwar Ul Islam ${ }^{3, *(D)}$ \\ 1 Department of Experimental Pathology, Faculty of Medicine, University of Tsukuba, Tsukuba, \\ Ibaraki 305-8575, Japan; a.haque5314@gmail.com \\ 2 Graduate School of Comprehensive Human Sciences, University of Tsukuba, Tsukuba, \\ Ibaraki 305-8575, Japan \\ 3 Department of Pharmacy, University of Rajshahi, Rajshahi 6205, Bangladesh \\ * Correspondence: anwar.pharm@ru.ac.bd; Tel.: +88-01716325611
}

Received: 23 August 2019; Accepted: 22 October 2019; Published: 28 October 2019

\begin{abstract}
Background and objectives: Mushrooms that have medicinal properties are part of many traditional diets. The aim of the present study was to use the human breast cancer cell line MCF-7 to investigate the anticancer activity of Pleurotus highking mushroom purified extract fraction-III (PEF-III) and to elucidate the possible mechanism of that activity. Materials and Methods: The effects of PEF-III on cell proliferation and viability were evaluated by a colony formation assay and an MTT assay, respectively. Cell morphological changes, annexin- $V$ phycoerythrin and propidium iodide (PI) staining, DNA fragmentation, and caspase $3 / 7$ activity assays were performed to determine the induction of apoptosis by PEF-III. The genes responsible for regulation of apoptosis were analyzed by means of Western blot analysis. In vitro tumor sphere formation assay was performed using a 3D sphere culture system. Results: PEF-III significantly reduced the proliferation and viability of MCF-7 cells. Cell shrinkage and rounding, and annexin-V phycoerythrin and PI staining followed by flow cytometry indicated that the cell death was due to apoptosis. Additionally, a laddering DNA pattern and increased levels of caspase-3/7 enzyme also corroborated the notion of apoptosis-mediated cell death. This incidence was further confirmed by upregulation of proapoptotic genes ( $p 53$ and its target gene, $B a x)$ and downregulation of the expression of an antiapoptotic gene (Bcl-2). PEF-III also reduced the size and number of the tumor spheres in 3D culture conditions. Conclusions: The anticancer activity of PEF-III is due to induction of apoptosis by a shift in the balance of proapoptotic and antiapoptotic genes. Therefore, the findings of the present study may open a path to exploring potential drug candidates from the P. highking mushroom for combating breast cancer.
\end{abstract}

Keywords: apoptosis; $\mathrm{Bax} / \mathrm{Bcl}-2$ ratio; breast cancer; caspase 3/7 activity; flow cytometry; MCF-7 cells; tumor sphere; 3D culture medium

\section{Introduction}

Cancer is one of the most devastating diseases, posing the threat of mortality to individuals worldwide despite promising advances in medical diagnosis and treatment [1]. To date, chemotherapy is one of the promising strategies to treat cancer. Numerous chemotherapeutic drugs isolated from natural sources, such as vincristine, vinblastine, bleomycin, paclitaxel, and camptothecin, are now used for cancer treatment. However, owing to the lack of specificity, low success rate, and risk of frequent recurrence associated with chemotherapy [2], new, safe, and effective anticancer drug candidates 
are urgently needed. Therefore, considerable attention has been focused on screening anticancer compounds from natural sources, including from medicinal plants [3].

As part of such a study, we focused on an edible and medicinal species of the oyster mushroom, the Pleurotus highking. From ancient times, oyster mushrooms have been considered throughout the world as a functional food and folk medicine [4]. They contain diverse biomolecules that are used for the treatment of various diseases including cancer [5]. Although a number of studies have already been conducted to explore the antibacterial and antifungal [6], anti-HIV [7], antitumoral [8], cytotoxic activity [9], antilipidemic [10], hyperglycemic and hypotensive [11], antiinflammatory [12], and immunomodulatory [13] properties of some species of oyster mushrooms, no reports have been published indicating the anticancer properties of the P. highking mushroom.

Chronic oxidative stress and inflammation are major risk factors for cancer development. Previous studies $[9,12]$ reported that $P$. highking is a promising source of antioxidant and antiinflammatory agents. Hence, we hypothesized that, by supplying antioxidant and antiinflammatory metabolites, $P$. highking may reduce the risk of cancer. Here, we investigated the anticancer activity of P. highking purified extract fraction-III (PEF-III) on the human breast cancer cell line MCF-7 and explored the possible mechanism behind that.

\section{Materials and Methods}

\subsection{Sample Collection}

P. highking is commercially cultivated in Bangladesh. It was collected from the National Mushroom Development and Extension Centre, Savar, Dhaka-1340, Bangladesh. The mushroom was identified by an expert taxonomist at the Department of Botany, University of Dhaka, Bangladesh, and a specimen voucher of the sample under No. 20130123 was deposited in the National Herbarium, Bangladesh. Any dust was removed with clean water, and the mushrooms were dried in the shade for 12 days and stored in a closed container.

\subsection{Extraction of Crude Mushroom Extract}

Authenticated, shade-dried, and cleaned mushrooms were crushed into a fine powder by use of a grinding machine. About $250 \mathrm{~g}$ of the powder was soaked in $800 \mathrm{~mL}$ ethanol (95\%) in an Erlenmeyer flask. The flask was then plugged with cotton and covered with aluminum foil for one week and stirred regularly. After incubation, the mixture was filtered, and the collected filtrate was then concentrated by use of a rotary evaporator under reduced pressure. A flask containing the concentrated extract was left in a vacuum dryer overnight.

\subsection{Fractionation of Extract}

The crude extract was fractionated by silica gel (60-230 mesh size) column chromatography using an increasing gradient of methanol in chloroform up to $100 \%$. About $20 \mathrm{~mL}$ of every eluate was collected and combined with others that had similar compositions in thin layer chromatography. Five isolated fractions were dried using a rotary evaporator. A stock solution of the fraction was prepared by dissolving it in dimethyl sulfoxide (DMSO), which was further diluted with cell culture medium (DMEM; Dulbecco's modified eagle media). Then, the test solutions were filtered through a $0.22 \mu \mathrm{m}$ membrane filter and stored in $-20^{\circ} \mathrm{C}$ for further experiments.

\subsection{Cell Line and Cell Culture}

Cells from the breast cancer cell line MCF-7, obtained from the American type culture collection (ATCC), were cultured in DMEM and supplemented with 10\% fetal bovine serum (FBS; Gibco, Waltham, MA, USA), $100 \mathrm{U} / \mathrm{mL}$ penicillin G, and $0.1 \mathrm{mg} / \mathrm{mL}$ streptomycin sulfate (Fujifilm Wako Pure Chemical Corporation, Osaka, Japan). The cells were incubated in a humidified atmosphere $\left(5 \% \mathrm{CO}_{2}\right.$ at $\left.37^{\circ} \mathrm{C}\right)$. Before start of the experiments, the cells were checked for mycoplasma contamination. 


\subsection{Colony Formation Assay}

About 400 MCF-7 cells were seeded in each well of a 6-well plate. After $24 \mathrm{~h}$, the cells were treated at different concentrations $\left(20\right.$ and $30 \mu \mathrm{g} / \mathrm{mL}$ ) of PEF-III and incubated at $37^{\circ} \mathrm{C}$ and $5 \% \mathrm{CO}_{2}$ for 15 days. The cells were washed twice in PBS (Phosphate buffer saline), fixed in $4 \%$ formaldehyde, and stained with $0.01 \%$ crystal violet solution. Photographs of the fixed colonies were taken with a DSLR camera, and the colonies were counted by use of Image J software (National Institutes of Health, NIH). The following formula was used to calculate the colony formation rate: colony formation rate $=$ (number of colonies after 15 days/number of cells seeded initially) $\times 100$.

\subsection{Cell Viability/Proliferation Assay}

Cell viability was measured using the MTT (3-[4,5-dimethylthiazol-2-yl]-2,5-di-phenyltetrazolium bromide) assay. Briefly, $5 \times 10^{3}$ cells/well were seeded in a 96-well plate and incubated at $37^{\circ} \mathrm{C}$ and $5 \% \mathrm{CO}_{2}$ with different concentrations (20 and $30 \mu \mathrm{g} / \mathrm{mL}$ ) of PEF-III for $24 \mathrm{~h}$. Then, MTT was added to the wells $(100 \mu \mathrm{g} /$ well $)$, and the cells were incubated under the same conditions. An ELISA (enzyme-linked immunosorbent assay) microplate reader (BioTek Instruments, Winooski, VT, USA) was used to measure the absorbance at $595 \mathrm{~mm}$. The results were expressed as the percentage of the control, which was considered to be $100 \%$, and the plotted absorbance values were the means from three independent experiments.

\subsection{Morphological Study Using an Inverted Light Microscope}

The morphological study was performed according to a published report [14]. Briefly, $3 \times 10^{5}$ cells were seeded in each well of 6-well plate and incubated for $24 \mathrm{~h}$ for attachment. Then, the medium was removed and fresh medium containing 20 and $30 \mu \mathrm{g} / \mathrm{mL}$ of PEF-III was added, and both the treated and the untreated cells were again incubated for $72 \mathrm{~h}$. After incubation, morphological alteration of the cells was observed under an inverted light microscope (Olympus, Tokyo, Japan).

\subsection{Annexin V-Phycoerythrin and PI Staining for Apoptosis}

Next, to find out the causes of the anti-proliferative effect of the PEF-III, an apoptosis-indicating experiment, annexin V-phycoerythrin and propidium iodide (PI)- staining, was performed. First, the MCF-7 cells $\left(1 \times 10^{6}\right)$ were plated in a $10-\mathrm{cm}$ dish and incubated at $37^{\circ} \mathrm{C}$ and $5 \% \mathrm{CO}_{2}$ for $24 \mathrm{~h}$. The cells were then treated with PEF-III and incubated for 2 days, after which they were washed in PBS twice, trypsinized, and resuspended in $100 \mu \mathrm{L}$ of annexin-binding buffer (BD Company, Franklin Lakes, NJ, USA). After that, the resuspended cells were stained with annexin V-phycoerythrin (BD Company) and PI (BD Company) at a ratio of 1:10 and subjected to flow cytometry. FlowJo software (Tree Star, Ashland, OR, USA) was used for the apoptosis analysis.

\subsection{Investigation of DNA Fragmentation}

For confirmation of cell death through apoptosis, a DNA fragmentation assay was performed using the agarose gel electrophoresis method described previously [15]. In brief, about $1 \times 10^{6}$ cells were seeded in each well and incubated for $24 \mathrm{~h}$. The cells were then treated with different concentrations (20 and $30 \mu \mathrm{g} / \mathrm{mL}$ ) of PEF-III and incubated again for $48 \mathrm{~h}$. After the incubation, the cells were washed in PBS and resuspended again in PBS. Total DNA was isolated using a DNA extraction kit (Promega, Madison, WI, USA), analyzed by electrophoresis on $1 \%$ gel containing $0.1 \mu \mathrm{g} / \mathrm{mL}$ of ethidium bromide and visualized under a UV illuminator.

\subsection{Caspase 3/7 Activity Assay}

To investigate the mechanism of apoptosis, a caspase activity assay was performed according to the manufacturer's protocol (Promega). First, $6 \times 10^{3}$ cells/well were seeded in a 96-well clear-bottom white-walled plate containing $100 \mu \mathrm{L}$ of DMEM, treated with different concentrations of PEF-III (20 and 
$30 \mu \mathrm{g} / \mathrm{mL}$ ), and the cells were incubated for $24 \mathrm{~h}$. Then, $100 \mu \mathrm{L}$ of the assay kit was added and the cells were kept at room temperature for $2 \mathrm{~h}$. Luminescence was measured using a fluorescence/multidetection microplate reader (BioTek Instruments).

\subsection{SDS-PAGE and Western Blot Analysis}

SDS-PAGE and Western blot analysis were performed according to the protocol described previously [16]. Briefly, cells were seeded in a 6-well plate, and after $24 \mathrm{~h}$, treated with or without PEF-III (20 and $30 \mu \mathrm{g} / \mathrm{mL}$ ) and incubated till $70-80 \%$ confluence. Lysates were prepared using lysis buffer (50 mM TrisCl, pH 7.8, $150 \mathrm{mM} \mathrm{NaCl}, 1 \% \mathrm{NP} 40,0.1 \%$ SDS, $1 \mathrm{mM}$ phenylmethylsulfonyl fluoride). The lysates were then resolved on SDS-PAGE and transferred into polyvinylidene difluoride (PVDF) membranes. Next, the membranes were blocked in skim milk $(4 \%)$ and Tris-buffered solution $(50 \mathrm{mM}$ Tris-HCl, pH 7.4, $150 \mathrm{mM} \mathrm{NaCl}, 0.1 \%$ Tween-20) for $1 \mathrm{~h}$ and incubated overnight at $4{ }^{\circ} \mathrm{C}$ with specific primary antibodies including anti-human Bcl-2 (Abcam, Tokyo, Japan), Bax (Cell Signaling Technology, Tokyo, Japan), p53 (Cell Signaling Technology), and $\beta$-actin (Cell Signaling Technology). After that, the membranes were incubated with horseradish peroxidase conjugated secondary antibodies for 50 min and then washed with Milli-Q (3-4 times), after which bound antibodies were detected by chemiluminescence reaction using Immuno Star Zeta (Wako) and EZ capture MG (ATTO Corporation, Tokyo, Japan) according to the manufacturers' protocols.

\subsection{In Vitro Tumor Sphere Formation Assay}

Tumor sphere culture is a recently developed technique that is now widely used in drug screening for antitumor activity. Tumor sphere culture is a simple, inexpensive, and effective method for providing a physiological environment that closely resembles that of culture cells [17]. In vitro tumor sphere assay was performed according to the reported protocol [18]. Briefly, about $3 \times 10^{3}$ cells were seeded in each well of a polyhema coated 6-well plate containing 3D sphere medium that contain either DMSO or PEF-III. The cells were incubated for 5 days and the tumor sphere size and number were calculated using an Olympus microscope.

\subsection{Statistical Analysis}

All the experiments were conducted in triplicate. The experimental data were expressed as means \pm standard deviations (SDs) using Microsoft Excel software (iOS version 2011; Microsoft, Washington, DC, USA). When two values were compared (control vs. treatment), significance was assessed using the unpaired $t$ test. Probability values lower than 0.05 were considered significant.

\section{Results}

\subsection{PEF-III Decreases Proliferation of Breast Cancer Cells}

To explore the anticancer effect of PEF-III on the breast cancer cell line MCF-7, proliferation of the cells was examined through colony formation and MTT assays. The PEF-III significantly reduced the colony-forming ability of the treated cells ( 21 and $42 \%$ at doses of 20 and $30 \mu \mathrm{g} / \mathrm{mL}$, respectively) when compared with the untreated cells (Figure 1A,B). A similar trend was also observed in the MTT assay. When the cells were challenged with different concentrations of PEF-III, the number of viable cells was significantly decreased when compared with that of the untreated cells (Figure 1C). These results revealed that the PEF-III has strong anticancer activity against these treated breast cancer cells. 

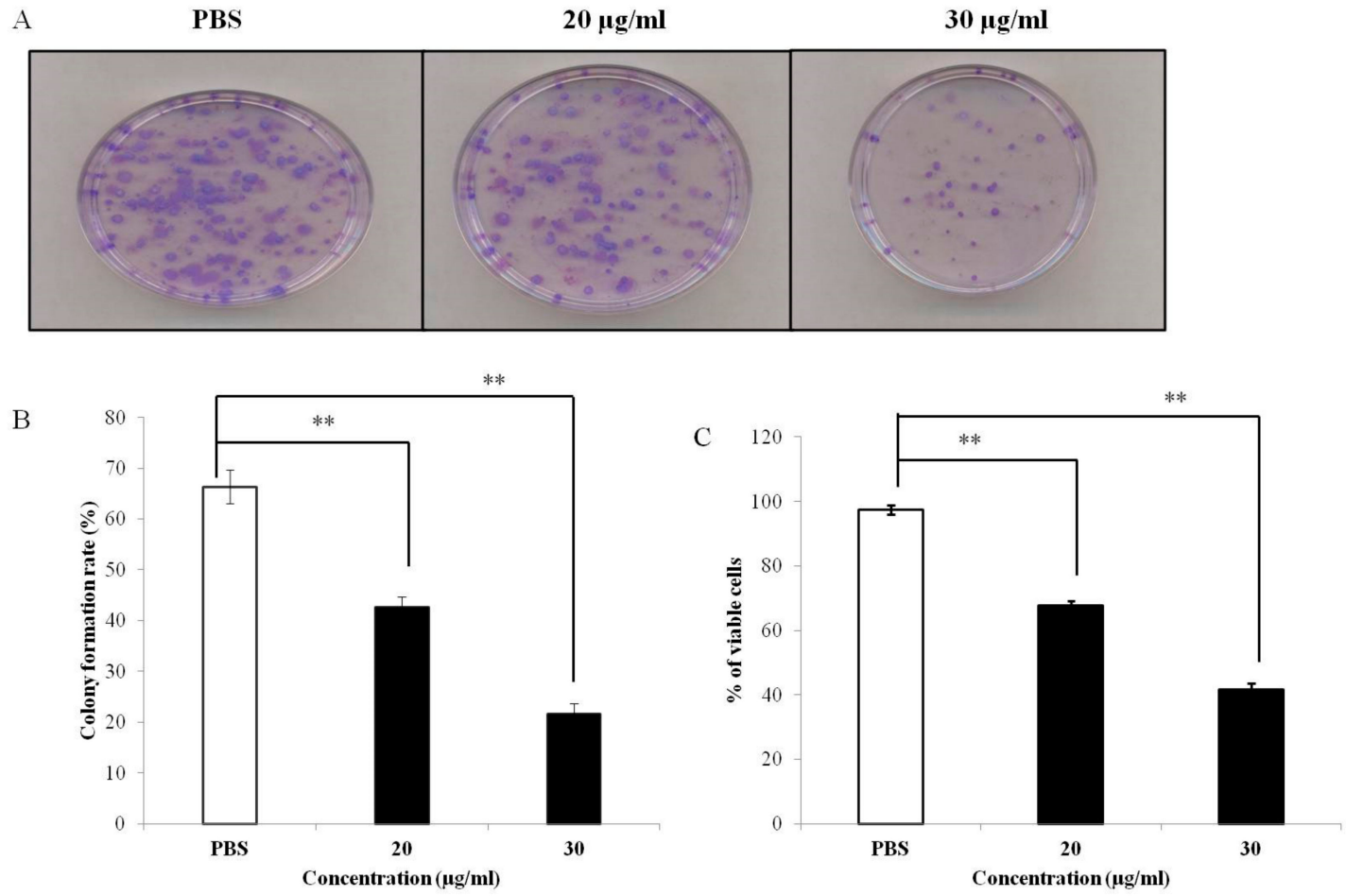

Figure 1. Inhibition of MCF-7 cell growth by Pleurotus highking extract fraction-III (PEF-III). The cells were treated with different concentrations of PEF-III $(20$ and $30 \mu \mathrm{g} / \mathrm{mL})$ and, incubated for 2 weeks, after which the colony was visualized by staining with crystal violate (A). The bar chart (B) depicts the quantification of the colony formation rate as compared with that of the control. After treatment with the indicated concentration of the extract, the cell viability was measured using the MTT assay (C). Values presented here are the means \pm SDs of three independent experiments. Bars with asterisks indicate significant difference from the control at $P \leq 0.05\left(^{*}\right)$ or $P \leq 0.01\left(^{* *}\right)$.

\subsection{PEF-III Induced Apoptosis-Related Morphological Characteristics}

The number of treated cells was significantly reduced at $72 \mathrm{~h}$ posttreatment when compared with the untreated cells. Cell detachment, cell rounding, cytoplasmic condensation, and cell shrinkage (Figure 2), which are the characteristics of apoptosis, were observed in the treated cells.
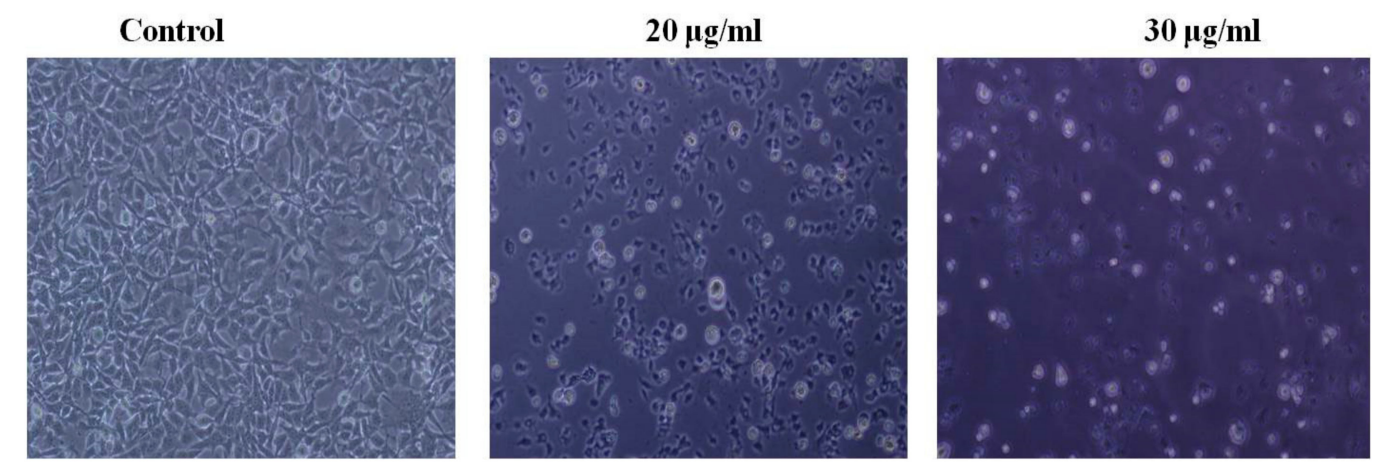

Figure 2. Morphological changes of PEF-III challenged cells under an inverted light microscope. The cells treated with 20 and $30 \mu \mathrm{g} / \mathrm{mL}$ of PEF-III exhibited morphological changes, and apoptosis related characteristics such as cell shrinkage and rounding and detachment from the culture dishes were observed (100× magnifications). 


\subsection{PEF-III Induces Cell Death through Apoptosis}

To determine the mode of PEF-III mediated cell death, we performed a double-label staining annexin-V phycoerythrin and PI-binding experiment. As shown in Figure 3A, PEF-III induced apoptosis in a concentration-dependent manner, i.e., $76.5 \%$ and $81.7 \%$ apoptosis at doses of 20 and $30 \mu \mathrm{g} / \mathrm{mL}$, respectively, as compared with the DMSO-treated cells. From these data, it was clear that PEF-III potentiates cell death by inducing apoptosis.
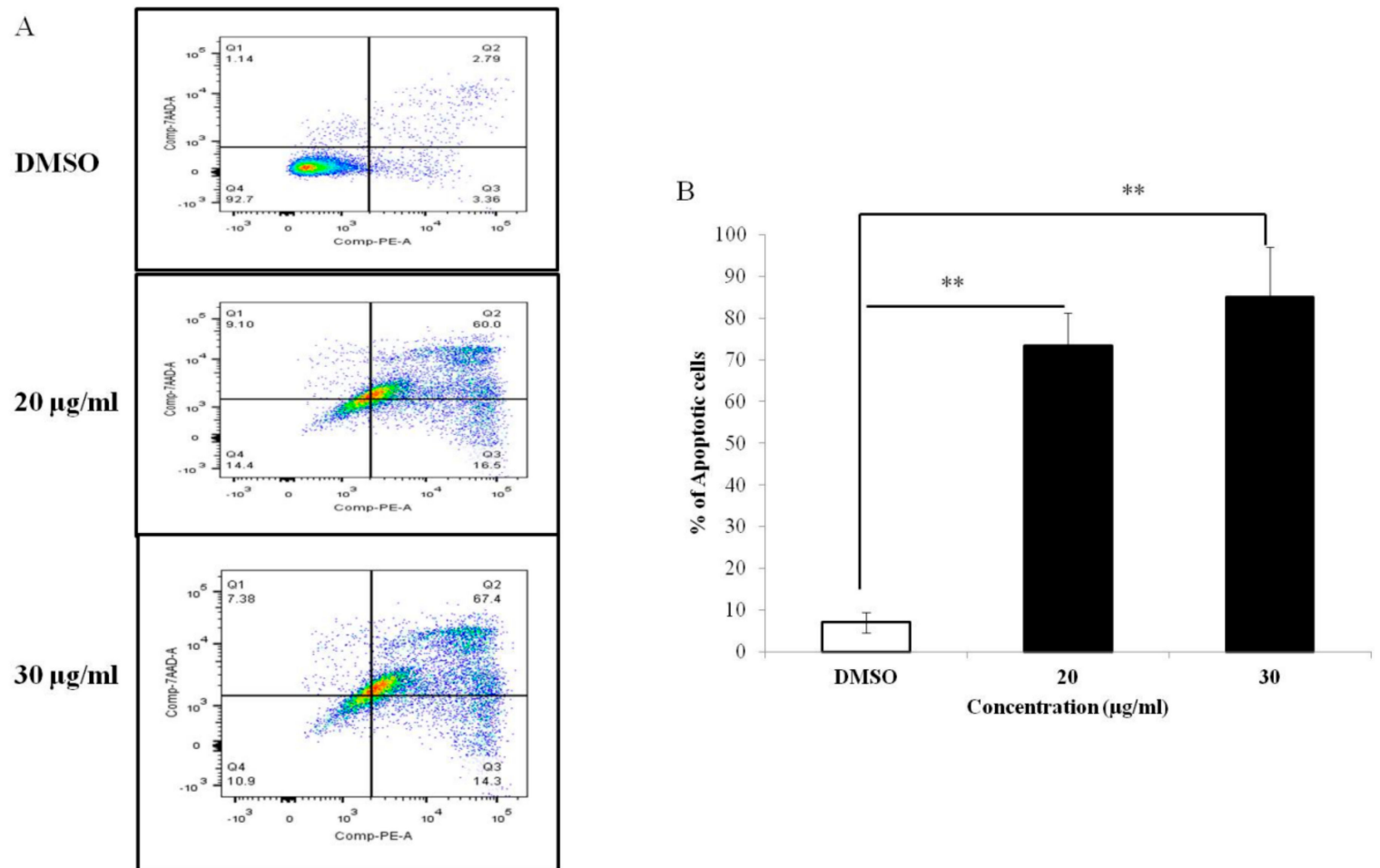

Figure 3. Apoptosis-inducing effect of PEF-III in the breast cancer cell line MCF-7. The cells were treated with different concentrations of the purified extract $(20$ and $30 \mu \mathrm{g} / \mathrm{mL})$ and, stained with annexin V-PE and propidium, and apoptosis was measured by flow cytometry (A). The bar chart (B) shows the percentage of apoptotic induction by the extract as compared with that by the control. Values presented here are the means \pm SDs of three independent experiments. The bars with asterisks indicate significant difference from the control at $P \leq 0.05\left(^{*}\right)$ or $P \leq 0.01\left({ }^{* *}\right)$.

\subsection{PEF-III Induces DNA Fragmentation and Increases Caspase 3/7 Activity}

Further, to determine if PEF-III mediated cell death is due to apoptosis, a DNA fragmentation assay was performed. As shown in Figure 4A, a laddering pattern of genomic DNA was observed in the treated cells. These data indicate internucleosomal DNA degradation due to apoptosis. Additionally, to elucidate the molecular mechanism of apoptosis induced by PEF-III, we measured caspase 3/7 activity. As shown in Figure 4B, PEF-III increased the caspase 3/7 activity significantly when compared with the untreated cells. These data support the notion that PEF-III induced apoptosis through an intrinsic pathway. 

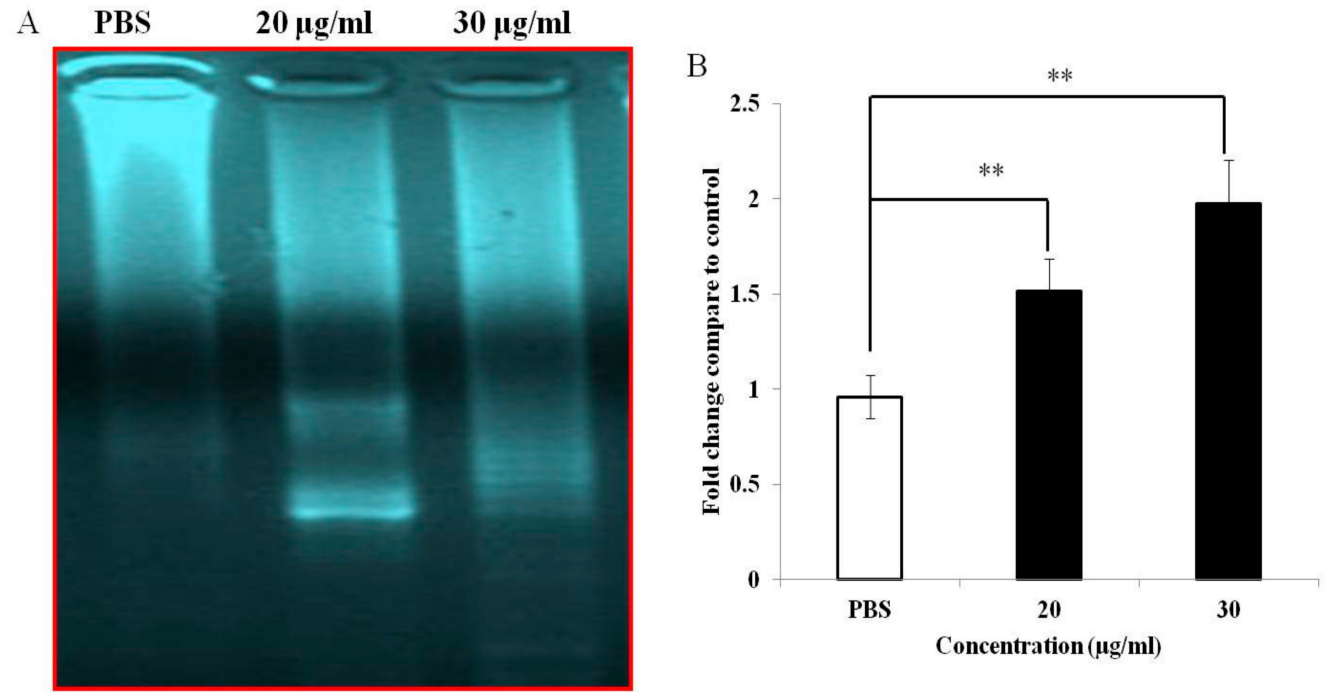

Figure 4. Effects of PEF-III on DNA fragmentation and caspase 3/7 activity in MCF-7 cells. Treated (20 and $30 \mu \mathrm{g} / \mathrm{mL}$ of PEF-III) and untreated cells were collected. The total genomic DNA of the cells was then run in $1 \%$ agarose gel containing $0.1 \mu \mathrm{g} / \mathrm{mL}$ ethidium bromide and visualized under a UV illuminator (A). Both the treated and the untreated cells were stained with aminoluciferin labeled substrate caspase, the lysates were incubated with caspase 3/7, and the luminescence (caspase 3/7 activity) was measured (B). Data are expressed as fold changes in comparison with the untreated (control) cells. Data for caspase 3/7 activity are presented as the means \pm SDs of three independent experiments. The bars with asterisks indicate significant difference from the control at $P \leq 0.05\left(^{*}\right)$ or $P \leq 0.01{ }^{(* *)}$.

\subsection{PEF-III Alters the Expression of Proapoptotic and Antiapoptotic Genes}

As apoptosis or programmed cell death is tightly regulated by various genes, we performed Western blot analysis to examine whether PEF-III affects the expression of proapoptotic genes such as p53, and Bax as well as the expression of antiapoptotic genes such as Bcl-2. The result revealed that in PEF-III treated MCF-7 cells, the expression levels of p53 and Bax were increased (Figure 5A) whilst the expression level of Bcl-2 was significantly decreased (Figure 5A and their corresponding densiometric analysis are shown in Figure 5B [Bcl-2], 5C [Bax], and 5D [p53]) as compared with the control. This result corroborates the notion that the mechanism by which PEF-III induces cell death through apoptosis is by altering the balance of proapoptotic and antiapoptotic genes. 

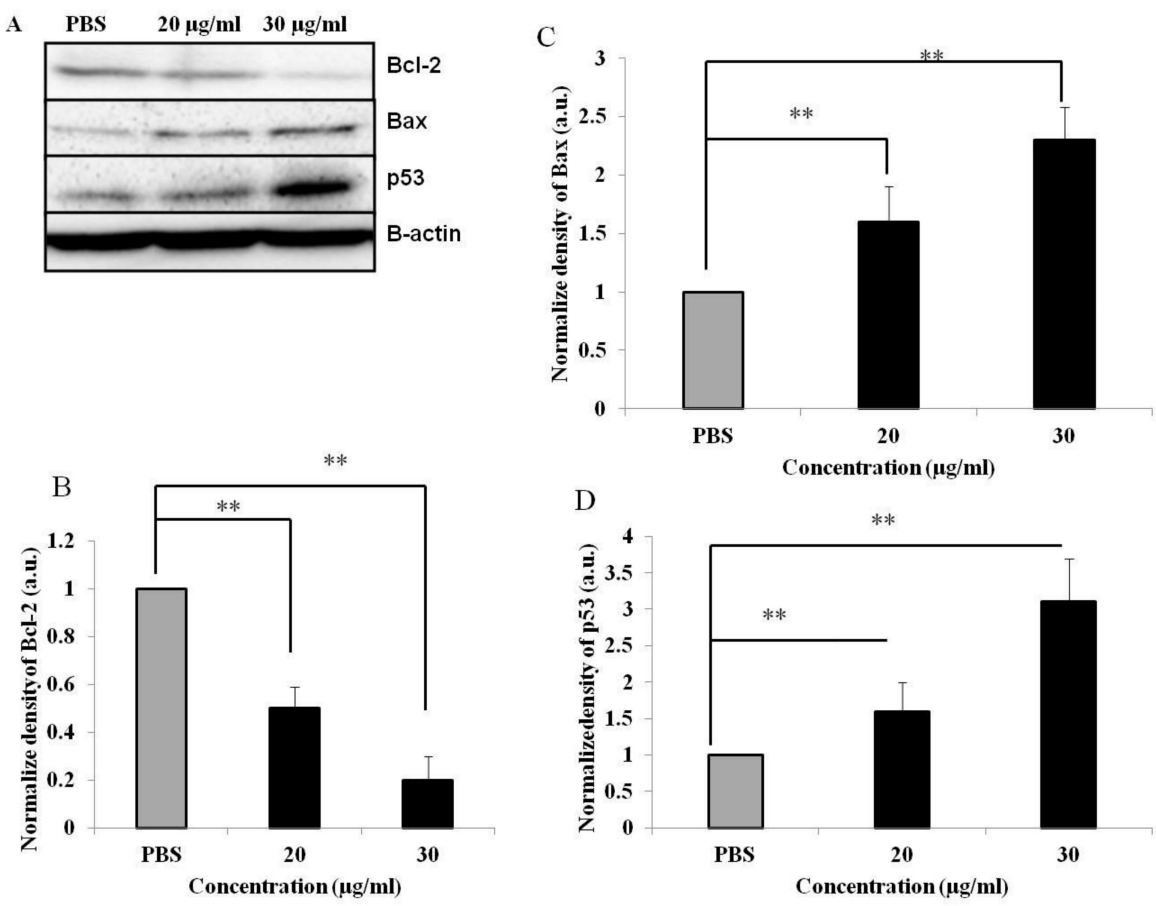

Figure 5. Western blot analysis of the expression of the proapoptotic and antiapoptotic genes. The expressions of the $B c l-2, B a x$, and $p 53$ genes were investigated by means of Western blot analysis in MCF-7 untreated and treated (20 and $30 \mu \mathrm{g} / \mathrm{mL}$ of PEF-III) cells (A). The $\beta$-actin expression confirmed the loading control and was also used to normalize the expression. The quantitative bars (B-D) show the respective normalized expressions of the $B c l-2, B a x$, and $p 53$ genes, which were measured by densitometry with Image-J software. Data are presented as the means \pm SDs of three independent experiments. The bars with asterisks indicate significant difference from the control at $P \leq 0.05\left(^{*}\right)$ or $P \leq 0.01\left({ }^{* *}\right)$.

\subsection{PEF-III Inhibits Tumor Sphere Formation}

In this study, we evaluated the effect of PEF-III on in vitro tumor sphere formation in a 3D culture system and found that PEF-III reduced the tumor sphere size (Figure 6A) and number (Figure 6B) significantly.

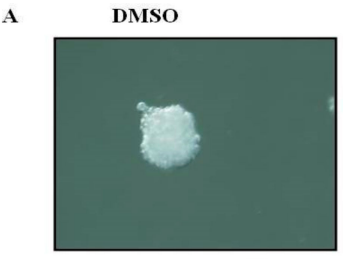

$20 \mu \mathrm{g} / \mathrm{ml}$

$30 \mu \mathrm{g} / \mathrm{ml}$
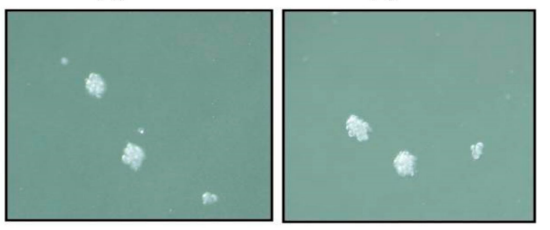

B

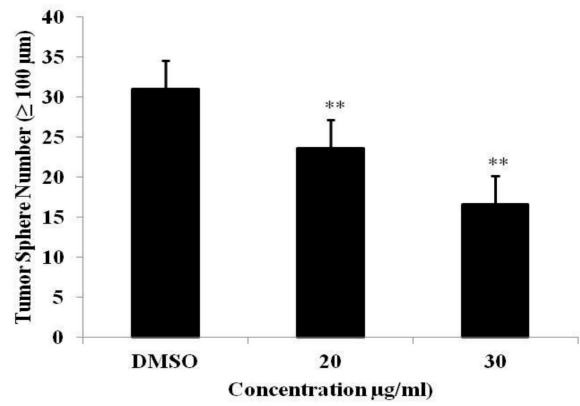

Figure 6. Effect of PEF-III on tumor sphere formation. Cells were cultured in a 3D sphere-forming medium with or without PEF-III and after 5 days' incubation; the size (A) and number (B) of the tumor spheres were measured. Data are presented as the means \pm SDs of three independent experiments. The bars with asterisks indicate significant difference from the control at $P \leq 0.05\left(^{*}\right)$ or $P \leq 0.01\left(^{* *}\right)$. 


\section{Discussion}

Owing to the abundance of antioxidants and other medicinal constituents present in certain medicinal plants, intake of certain plant products is always inversely correlated with development of cancer [19]. In this study, we used P. highking extract fraction-III (PEF-III) to evaluate its anticancer activity against the breast cancer cell line MCF-7. We identified the mechanism of PEF-III mediated cell death and the genes responsible for that. Among five fractions, only fraction-III showed strong antiproliferative activity (data not shown) against breast cancer cells: its $\mathrm{IC}_{50}$ value was $24 \mu \mathrm{g} / \mathrm{mL}$.

We found that PEF-III significantly reduced the colony numbers as compared with those of the untreated cells (Figure 1A,B). This was corroborated by a decrease in the number of viable cells during the MTT assay (Figure 1C). A similar result was reported by Andrej et al. [20], who used another species of oyster mushroom. Our data clearly show that the extract induced alteration of the growth kinetic in the tested cells.

To investigate the possible mechanism of cell death induced by PEF-III, we performed apoptosis-related experiments. First, we observed cell detachment from culture plates, cell shrinkage, and cell rounding (Figure 2) under an inverted light microscope in PEF-III treated cells. We also used double-label staining, annexin-V/PI followed by flow cytometry. Annexin-V usually binds with phosphatidylserine (PS). In healthy cells, PS is located on the inner side of the plasma membrane and annexin-V cannot bind with PS [21]. During the early apoptotic stage, PS translocates to the external membrane and annexin-V then specifically binds with PS and identifies the apoptotic cells. At the late stage, apoptotic cells and necrotic cells will stain positively owing to the passage of these dyes into the nucleus where they bind with DNA [22]. Our flow cytometric data (Figure 3A) revealed that PEF-III potentiates cell death by inducing apoptosis in a dose-dependent manner. Moreover, the DNA fragmentation (Figure 4A) and caspase 3/7 enzyme activation (Figure 4B) results led us to conclude that the cell death was due to apoptosis.

Cancer cells survive in a number of pathways. One common pathway is escape from apoptosis by downregulation of proapoptotic genes ( $p 53$ and $B a x$ ) and hyperactivation of antiapoptotic genes $(B c l-2$ and $B c l-x L)$ [23]. Therefore, induction of apoptosis in cancer cells is considered a good strategy to treat cancer.

It is well known that a cell commits to apoptosis by altering the balance of proapoptotic and antiapoptotic genes [24]. As $p 53$ induces apoptosis through upregulating the expression of proapoptotic signals (such as Bax and BH-3 only members), Bax affects the integrity of the mitochondrial membrane through making pores in the membrane which leads to the release of cytochrome-c. BH-3 members directly bind with Bax to increase its activity and at the same time bind with $\mathrm{Bcl}-2$ (antiapoptotic signals) to inhibit its activity, ultimately leading to cell death $[25,26]$.

In our study, we found that PEF-III upregulated the expression of $p 53$, which is responsible for the upregulation of $B a x$ and the downregulation of $B c l-2$ (Figure $5 \mathrm{~A}$ ) and hence increases the $\mathrm{Bax} / \mathrm{Bcl}-2$ ratio, which promotes apoptosis and cell death. This finding suggests that a critical determinant of the overall propensity of cells underwent apoptosis as a result of the aforementioned treatment. From these data, it is clear that PEF-III induces apoptosis by shifting the balance between proapoptotic and antiapoptotic genes. In the tumor sphere formation assay, we observed that PEF-III treatment decreased the number of tumor spheres as compared with that of the untreated cells (Figure 6A,B).

\section{Conclusions}

Taken together, the findings of this study lead us to conclude that PEF-III possesses strong anticancer activity via induction of apoptosis by alteration of the balance of apoptosis-related genes. Therefore, further in-depth studies will be required to isolate the bioactive compound responsible for that activity. Additionally, we believe that this study will act as an eye-opener regarding the anticancer effect of $P$. highking and will serve as a base for future research to isolate a potent chemopreventive agent. 
Author Contributions: Formal analysis, M.A.H.; investigation, M.A.H.; methodology, M.A.H.; supervision, M.A.U.I.; writing—original draft, M.A.H.; writing—review and editing, M.A.H. and M.A.U.I.

Funding: This research did not receive any specific grant from funding agencies in the public, commercial, or not-for-profit sectors.

Acknowledgments: P. highking mushrooms were kindly provided by the National Mushroom Development and Extension Centre, Savar, Dhaka-1340, Bangladesh. F. Miyamasu (Medical English Communications Center, University of Tsukuba, Ibaraki, Japan) proofread and edited the manuscript excellently. We would like to express our deep appreciation for all of these contributions.

Conflicts of Interest: All the authors read the manuscript and have given permission for it to be submitted to this journal. We have no conflicts of interest to declare.

\section{References}

1. Dolai, N.; Islab, A.; Haldar, P.K. Antiproliferative activity and apoptosis inducing mechanism of Anthocephalus cadamba on Dalton's lymphoma ascites cells. Iran. J. Pharm. Res. 2016, 15, 505-514. [PubMed]

2. Salem, M.L.; Shoukry, N.M.; Teleb, W.K.; Abdel-Daim, M.M.; Rahman, M.A.A. In vitro and in vivo antitumor effects of the Egyptian scorpion Androctonus amoreuxi venom in an Ehrlich ascites tumor model. Springerplus 2016, 5, 570. [CrossRef] [PubMed]

3. Chatterjee, S.; Biswas, G.; Chandra, S.; Saha, G.K.; Acharya, K. Apoptogenic effects of Tricholoma giganteum on Ehrlich's ascites carcinoma cell. Bioprocess Biosyst. Eng. 2013, 36, 101-107. [CrossRef] [PubMed]

4. Kim, T.A. Mushrooms: The ultimate health food but little research in U.S to prove it. Mushroom News. 1993, 41, 29-46.

5. Bala, N.; Aitken, E.A.B.; Fechner, N.; Cusack, A.; Steadman, K.J. Evaluation of antibacterial activity of Australian basidiomycetous macrofungi using a high-throughput 96-well plate assay. Pharm. Biol. 2011, 49, 492-500. [CrossRef]

6. Haque, M.A.; Sarker, A.K.; Khatun, A.; Islam, M.S.; Islam, M.A.U.; Anisuzzaman, A.S.M. Evaluation of susceptibility of methanol extract of Pleurotus highking, an edible mushroom cultivated in Bangladesh. Int. J. Sci. Technol. Res. 2014, 3, 275-278.

7. Piraino, F.; Brandt, C.R. Isolation and partial characterization of an antiviral, RC-183, from the edible mushroom Rozites caperata. Antivir. Res. 1999, 3, 67-78. [CrossRef]

8. Maiti, S.; Mallick, S.K.; Bhutia, S.K.; Behera, B.; Mandal, M.; Maiti, T.K. Antitumor effect of culinary-medicinal oyster mushroom, Pleurotus ostreatus (Jacq.: Fr.) P. Kumm., derived protein 84 fraction on tumor-bearing mice models. Int. J. Med. Mushrooms 2011, 13, 427-440. [CrossRef]

9. Haque, M.A.; Rana, M.M.; Aktar, K.; Haque, M.U.; Chouduri, M.A.U.; Islam, M.A.U. In-vitro antioxidant and cytotoxic activity of crude extracts of Pleurotus highking, a potential oyster mushroom. Br. J. Pharm. Res. 2017, 14, BJPR.30594. [CrossRef]

10. Alam, N.; Yoon, K.N.; Lee, T.S. Antihyperlipidemic activities of Pleurotus ferulae on biochemical and histological function in hypercholesterolemic rats. J. Res. Med. Sci. 2011, 16, 776-786.

11. Miyazawa, N.; Okazaki, M.; Ohga, S. Antihypertensive effect of Pleurotus nebrodensis in spontaneously hypertensive rats. J. Oleo Sci. 2008, 57, 675-681. [CrossRef] [PubMed]

12. Nosalova, V.; Bobek, P.; Cerna, S.; Galbavy, S.; Stvrtina, S. Effects of pleuran (beta glucan isolated from Pleurotus ostreatus) on experimental colitis in rats. Physiol. Res. 2001, 50, 5755-5781.

13. Wasser, S.P. Medicinal mushrooms as a source of antitumor and immunomodulating polysaccharides. Appl. Microbiol. Biotechnol. 2002, 60, 258-274. [PubMed]

14. Tor, Y.S.; Yazan, L.S.; Foo, J.B.; Armania, N.; Cheah, Y.K.; Abdullah, R.; Imam, M.U.; Ismail, N.; Ismail, M. Induction of apoptosis through oxidative stress-related pathways in MCF-7, human breast cancer cells, by ethyl acetate extract of Dillenia suffruticosa. BMC Compl. Alter. Med. 2014, 14, 55. [CrossRef] [PubMed]

15. Tayeb, K.; William, T.B. Merbarone, a catalytic inhibitor of DNA topoisomerase II, induces apoptosis in CEM cells through activation of ICE/CED-3-like protease. Mol. Pharmacol. 1999, 55, 548-556.

16. Wu, C.H.; Liu, F.C.; Pan, C.H.; Lai, M.T.; Lan, S.J.; Wu, C.H.; Sheu, M.J. Suppression of cell growth, migration and drug resistance by ethanolic extract of Antrodia cinnamomea in human lung cancer A549 cells and C57BL/6J allograft tumor model. Int. J. Mol. Sci. 2018, 19, 791. [CrossRef] 
17. Zhu, Z.W.; Chen, L.; Liu, J.X.; Huang, J.W.; Wu, G.; Zheng, Y.F.; Yao, K.T. A novel three-dimensional tumorsphere culture system for the efficient and low-cost enrichment of cancer stem cells with natural polymers. Exp. Ther. Med. 2018, 15, 85-92. [CrossRef]

18. Lee, C.H.; Yu, C.C.; Wang, B.Y.; Chang, W.W. Tumorsphere as an effective in vitro platform for screening anti-cancer stem cell drugs. Oncotarget 2016, 7, 1215-1226. [CrossRef]

19. Somasagara, R.R.; Hegde, M.; Chiruvella, K.K.; Musini, A.; Choudhary, B.; Raghavan, S.C. Extracts of strawberry fruits induce intrinsic pathway of apoptosis in breast cancer cells and inhibits tumor progression in mice. PLoS ONE 2012, 7, e47021. [CrossRef]

20. Andrej, J.; Daniel, S. Pleurotus ostreatus inhibits proliferation of human breast and colon cancer cells through p53-dependent as well as p53-independent pathway. Int. J. Oncol. 2008, 33, 1307-1313.

21. Yang, S.; Zhao, Q.; Xiang, H.; Liu, M.; Zhang, Q.; Xue, W.; Song, B.; Yang, S. Antiproliferative activity and apoptosis-inducing mechanism of constituents from Toona sinensis on human cancer cells. Cancer Cell Int. 2013, 13, 12-19. [CrossRef] [PubMed]

22. Bhattacharyya, A.; Choudhuri, T.; Pal, S.; Chattopadhyay, S.; Datta, G.K.; Sa, G.; Das, T. Apoptogenic effects of black tea on Ehrlich's ascites carcinoma cell. Carcinogenesis 2003, 24, 75-80. [CrossRef] [PubMed]

23. Hanahan, D.; Weinberg, R.A. The hallmarks of cancer. Cell 2000, 100, 57-70. [CrossRef]

24. Giannakakou, P.; Robey, R.; Fojo, T.; Blagosklonny, M.V. Low concentrations of paclitaxel induce cell type dependent p53, p21 and G1/G2 arrest instead of mitotic arrest: Molecular determinants of paclitaxel induced cytotoxicity. Oncogene 2001, 20, 3806-3813. [CrossRef]

25. Yu, J.; Zhang, L. PUMA, a potent killer with or without p53. Oncogene 2008, 27, S71-S83. [CrossRef]

26. Borner, C. The Bcl-2 protein family: Sensors and checkpoints for life-or-death decisions. Mol. Immunol. 2003, 39, 615-647. [CrossRef]

(C) 2019 by the authors. Licensee MDPI, Basel, Switzerland. This article is an open access article distributed under the terms and conditions of the Creative Commons Attribution (CC BY) license (http://creativecommons.org/licenses/by/4.0/). 